\title{
Efeito dos níveis de lisina digestível e da ractopamina sobre o desempenho e as características de carcaça de suínos machos castrados em terminação ${ }^{1}$
}

\author{
Paula Cambraia Marinho ${ }^{2}$, Dalton de Oliveira Fontes ${ }^{3}$, Francisco Carlos de Oliveira Silva ${ }^{4}$, \\ Martinho de Almeida e Silva ${ }^{3}$, Francisco Alves Pereira ${ }^{5}$, Cláudio Luiz Corrêa Arouca ${ }^{5}$ \\ 1 Projeto apoiado pela Elanco. \\ 2 Mestre em Zootecnia - Escola de Veterinária da UFMG. \\ ${ }^{3}$ Departamento de Zootecnia da Escola de Veterinária da UFMG. \\ 4 EPAMIG/CTZM, Viçosa - MG, CEP: 36571-000. \\ 5 Pós-Graduação - Escola de Veterinária da UFMG.
}

RESUMO - Foi conduzido um experimento com o objetivo de avaliar o efeito de diferentes níveis de lisina digestível em rações suplementadas ou não com ractopamina (RAC) sobre o desempenho e as características de carcaça de suínos machos castrados em terminação. Quarenta suínos, híbridos comerciais, foram distribuídos em delineamento experimental de blocos ao acaso, em arranjo fatorial 2 × 2 - dois níveis de lisina digestível (0,67 e 0,87\%), com ajuste para os demais aminoácidos para a relação de proteína ideal, e dois níveis de RAC (0 e 5,0 ppm) - em um período de 28 dias. A suplementação com RAC resultou em maiores ganho de peso diário e taxa de deposição de carne magra diária e melhor conversão alimentar. Os níveis de lisina não influíram no desempenho dos animais, porém reduziram a espessura de toucinho nos pontos $\mathrm{P}_{1}$ e $\mathrm{P}_{2}$ e aumentaram a taxa de deposição de carne magra diária na carcaça de suínos alimentados com dietas contendo 0,87\% de lisina digestível quando avaliadas in vivo. Concluiu-se que as características de desempenho e de carcaça dos suínos alimentados com ração suplementada com RAC na fase de terminação melhoraram, porém, o efeito da RAC sobre a profundidade de lombo foi maior no nível de $0,87 \%$ de lisina digestível.

Palavras-chave: aditivos, alimentação, aminoácidos, carne magra, exigência nutricional, nutrição

\section{Effect of digestible lysine levels and of ractopamine on the performance and carcass characteristics of finishing barrows}

\begin{abstract}
An experiment was carried out with the objective of evaluating the effect of different lysine levels in diets supplemented or not with ractopamine (RAC) on the performance and carcass characteristics of finishing barrows. Forty commercial hybrid swines were distributed to a randomized experimental block design, in a 2 × 2 factorial arrangement, with two digestible lysine levels ( 0.67 and $0.87 \%$ ), with adjustment for the others amino acids to achieve an ideal protein relationship, and two levels of RAC (0 and $5.0 \mathrm{ppm}$ ) in a period of 28 days. Supplementation with RAC resulted in a higher daily weight gain and of daily lean meat deposition rate, and better feed conversion. The lysine levels did not affect the performance of the animals, however there was a reduction of backfat thickness on $\mathrm{P}_{1}$ and $\mathrm{P}_{2}$ points and increased the daily lean meat deposition rate on the carcass of swine fed with diets containing $0.87 \%$ of digestible lysine when in vivo evaluated. In conclusion, performance and carcass characteristics of swine fed with diets supplemented with RAC in the finishing phase improved; however the effect of RAC on the loin depth was higher for the higher level of $0.87 \%$ of digestible lysine.
\end{abstract}

Key Words: addictive, amino acids, feeding, lean meat, nutrition, nutritional requirement

\section{Introdução}

Para suprir o mercado e incrementar o ganho em carne magra, alternativas nutricionais têm sido avaliadas com a finalidade de diminuir a deposição de gordura e aumentar a deposição de músculo na carcaça de suínos, elevando-se a eficiência produtiva dos animais. O uso de aditivos, principalmente os repartidores de nutrientes, é uma das alternativas.
A ractopamina (RAC), por proporcionar melhorias significativas no desempenho e nas características de carcaça dos suínos, tem sido bastante recomendada em rações formuladas em granjas comerciais para suínos em crescimento e terminação.

A RAC tem sido incluída em dietas com $16 \%$ de PB para suínos com peso corporal entre 41 e $109 \mathrm{~kg}$ (Apple et al., 2004). Entretanto, dietas formuladas para suínos em termi- 
nação podem ser suplementadas com aminoácidos sintéticos, visando atender à relação ideal de aminoácidos. Segundo Schinckel et al. (2003), a porcentagem de lisina na proteína depositada por suínos consumindo ração suplementada com RAC aumenta de 6,80 para 7,15\%. Portanto, a concentração de aminoácidos proposta com base na proteína ideal pode não ser suficiente para atender às exigências de suínos consumindo ração contendo RAC (Webster et al., 2002; Schinckel et al., 2003).

Entre os aminoácidos essenciais, a lisina é considerada o primeiro aminoácido limitante para suínos e seu nível de inclusão deve ser aumentado nas dietas que contenham RAC. Além disso, os ajustes dos demais aminoácidos em relação à lisina devem ser observados durante a formulação destas dietas (Yen et al., 1990).

Objetivou-se com esta pesquisa avaliar os efeitos dos níveis de lisina digestível (0,67 e 0,87\%), com o ajuste dos demais aminoácidos para relação ideal, associados a dois níveis de ractopamina (0 e 5 ppm), sobre o desempenho, a composição corporal e as características de carcaça de suínos machos castrados em terminação.

\section{Material e Métodos}

O experimento foi conduzido no Setor de Suinocultura da Fazenda Experimental Vale do Piranga (EPAMIG), localizada no município de Oratórios, Minas Gerais. Os animais foram alojados em galpão de alvenaria com piso de concreto, coberto com telhas de amianto. As baias continham comedouros semi-automáticos, bebedouros tipo chupeta e dispunham de área de 1,87 $\mathrm{m}^{2} /$ animal. Foram utilizados termômetros, de máxima e mínima, colocados no interior do galpão para registro diário da temperatura durante todo o período experimental. As temperaturas mínimas e máximas do período experimental foram, respectivamente, $19 \pm 2^{\circ} \mathrm{C}$ e $28 \pm 2,8^{\circ} \mathrm{C}$.

Quarenta suínos machos castrados, híbridos comerciais originados de linhagens selecionadas geneticamente para deposição de carne magra, com peso inicial de $85,17 \pm 0,28 \mathrm{~kg}$, foram distribuídos em delineamento experimental de blocos ao acaso em arranjo fatorial 2 × 2 - dois níveis de lisina digestível (0,67 e 0,87\%), com ajuste para demais aminoácidos para a relação ideal, e dois níveis de RAC (0,0 e 5,0ppm)-, cinco repetições e dois animais por unidade experimental. Na distribuição dos animais, adotou-se como critério o peso inicial dos animais, cuja identificação foi individual, por meio de brincos.

As dietas experimentais (Tabela 1), à base de milho e farelo de soja, suplementadas com vitaminas, minerais e aminoácidos, foram formuladas segundo exigências mínimas descritas por Rostagno et al. (2000) para conterem 0,87\% de lisina digestível. O nível de 0,87\% de lisina digestível foi estabelecido porque os animais tratados com RAC devem consumir 30\% a mais de lisina para atingirem resultados significativos de desempenho e qualidade de carcaça (Mitchell et al., 1991; Xiao et al., 1999).

Nas dietas formuladas com base no conceito de proteína ideal (0,87\% de LD), foram utilizadas as relações de 62, 57 e 18\%, respectivamente, para treonina, metionina + cistina e triptofano com lisina (PIC, 1999). Às dietas formuladas foi adicionada ou não a RAC (0 e 5 ppm).

Durante todo o período experimental, as rações e a água foram pesadas periodicamente, ao passo que os animais foram pesados, individualmente, no início, aos 21 e aos 28 dias (final do período experimental) para determinação do peso final, do ganho de peso diário, da conversão alimentar, do consumo de ração diário e do consumo de lisina digestível diário.

As medidas ultra-sônicas in vivo das carcaças foram tomadas no início, aos 21 e 28 dias de experimento, após as pesagens dos animais, utilizando-se um equipamento portátil de ultra-som (Piglog $105^{\circledR}$ ). As medidas ultrasônicas foram tomadas a partir de pontos de leitura do aparelho obtidos sempre do lado esquerdo do animal: Ponto $P_{1}$ - medido a $6,5 \mathrm{~cm}$ da linha dorso-lombar e a $6,5 \mathrm{~cm}$ da última costela na direção caudal $\left(\mathrm{ETP}_{1}\right)$; Ponto $P_{2}$ - medido a 6,5 cm da linha dorso-lombar e a 6,5 cm da última costela na direção cranial $\left(\mathrm{ETP}_{2}\right)$ e a medida de profundidade de lombo (PL); Porcentagem de carne magra (PCM) - os preditores utilizados pelo aparelho para estimar o rendimento de carne magra foram a espessura de toucinho (nos pontos 1 e 2 ) e a profundidade de lombo (PL), determinando-se a porcentagem de carne magra do animal a partir dos valores obtidos; e Taxa de deposição de carne magra diária (TDCMD) - obtida dividindo-se a diferença entre a porcentagem de carne magra estimada no último dia e a porcentagem de carne magra no primeiro dia pelo número de dias em experimento.

Ao final do experimento, os animais com 121,31 \pm 4,00 kg foram encaminhados ao Frigorífico Industrial Vale do Piranga (FRIVAP), localizado no município de Ponte Nova - MG, para determinação das seguintes características de carcaça: pesagem da carcaça quente, rendimento de carcaça, pesagem da carcaça fria, rendimento de pernil, rendimento de carré, espessura de toucinho, profundidade de lombo e porcentagem de carne magra.

Os dados de desempenho e das características de carcaça foram analisados utilizando-se o pacote computacional 
Tabela 1 - Composições centesimal e calculadas das dietas experimentais

Table 1 - Percentage and calculated compositions of the experimental diet

\begin{tabular}{|c|c|c|c|c|}
\hline \multirow[t]{4}{*}{$\begin{array}{l}\text { Ingrediente (\%) (\%) } \\
\text { Ingredient }\end{array}$} & \multicolumn{4}{|c|}{$\begin{array}{l}\text { Nível de lisina (\%) } \\
\text { Lysine level }\end{array}$} \\
\hline & 0,67 & 0,67 & 0,87 & 0,87 \\
\hline & \multicolumn{4}{|c|}{$\begin{array}{l}\text { Nível de ractopamina (ppm) } \\
\text { Ractopamine level }\end{array}$} \\
\hline & 0,0 & 5,0 & 0,0 & 5,0 \\
\hline $\begin{array}{l}\text { Farelo de milho } \\
\text { Corn meal }\end{array}$ & 75,630 & 75,630 & 75,630 & 75,630 \\
\hline $\begin{array}{l}\text { Farelo de soja } \\
\text { Soybean meal }\end{array}$ & 21,110 & 21,110 & 21,110 & 21,110 \\
\hline $\begin{array}{l}\text { Fosfato bicálcico } \\
\text { Dicalcium phosphate }\end{array}$ & 1,190 & 1,190 & 1,190 & 1,190 \\
\hline $\begin{array}{l}\text { Calcário } \\
\text { Limestone }\end{array}$ & 0,820 & 0,820 & 0,820 & 0,820 \\
\hline $\begin{array}{l}\text { Sal } \\
\text { Salt }\end{array}$ & 0,400 & 0,400 & 0,400 & 0,400 \\
\hline $\begin{array}{l}\text { Premix vitamínico }{ }^{1} \\
\text { Vitamin mix }\end{array}$ & 0,300 & 0,300 & 0,300 & 0,300 \\
\hline $\begin{array}{l}\text { Premix mineral }{ }^{2} \\
\text { Mineral mix }\end{array}$ & 0,100 & 0,100 & 0,100 & 0,100 \\
\hline $\begin{array}{l}\text { Tilosina }^{3} \\
\text { Tilosin }\end{array}$ & 0,080 & 0,080 & 0,080 & 0,080 \\
\hline $\begin{array}{l}\text { Suplemento de } \mathrm{Cu}^{4} \\
\text { Cu supplement }\end{array}$ & 0,040 & 0,040 & 0,040 & 0,040 \\
\hline Paylean ${ }^{\circledR}$ & 0,000 & 0,025 & 0,000 & 0,025 \\
\hline Inerte & 0,330 & 0,305 & 0,037 & 0,012 \\
\hline Inert & & & & \\
\hline L-Lys $\mathrm{HCl}$ & 0,000 & 0,000 & 0,262 & 0,262 \\
\hline L-Thr & 0,000 & 0,000 & 0,026 & 0,026 \\
\hline DL-met & 0,000 & 0,000 & 0,005 & 0,005 \\
\hline
\end{tabular}

Valores nutricionais

calculados ${ }^{5}$

Calculated composition

\begin{tabular}{lcccc}
\hline Ca (\%) & 0,700 & 0,700 & 0,700 & 0,700 \\
EM (kcal/kg) & 3.182 & 3.182 & 3.182 & 3.182 \\
ME (kcal/kg) & & & & \\
$\begin{array}{l}\text { PB (\%) CP (\%) } \\
\text { P disponível (\%) }\end{array}$ & 16,10 & 16,10 & 16,10 & 16,10 \\
$\begin{array}{l}\text { Available P } \\
\text { Lisina digestível (\%) }\end{array}$ & 0,320 & 0,320 & 0,320 & 0,320 \\
$\begin{array}{l}\text { Digestible lysine } \\
\text { Metionina + cistina }\end{array}$ & 0,493 & 0,670 & 0,875 & 0,875 \\
$\begin{array}{l}\text { digestível (\%) } \\
\text { Digestible methionine plus cystine }\end{array}$ & & 0,498 & 0,498 \\
$\begin{array}{l}\text { Thr digestível (\%) } \\
\text { Digestible Thr }\end{array}$ & 0,516 & 0,516 & 0,542 & 0,542 \\
$\begin{array}{l}\text { Trp digestível (\%) } \\
\text { Digestible Trp }\end{array}$ & 0,159 & 0,159 & 0,159 & 0,159 \\
$\begin{array}{l}\text { Ractopamina (ppm) } \\
\text { Ractopamine (ppm) }\end{array}$ & 0,0 & 5,0 & 0,0 & 5,0 \\
\hline
\end{tabular}

${ }^{1}$ Composição por kg de produto (Composition/kg of product): ácido fólico (folic acid), 116,55 mg; ácido pantotênico (pantothenic acid), $2.333,5 \mathrm{mg}$; biotina (biotin), 5,28 mg; niacina (niacin), $5.600 \mathrm{mg}$; piridoxina (piridoxine), $175 \mathrm{mg}$; riboflavina (riboflavin), 933,3 mg; tiamina (thiamin), $175 \mathrm{mg}$; Vit. A, 1.225.000 U.I.; Vit. D 315.000 U.I.; Vit. E, 1.400 mg; Vit. K, 700 mg; Vit. $\mathrm{B}_{12}, 6.825 \mathrm{mg}$; Se, $105 \mathrm{mg}$; antioxidante (antioxidant) $1.500 \mathrm{mg}$.

${ }^{2}$ Composição por kg de produto (Composition/kg of product): Ca, $98.800 \mathrm{mg}$; Co, 185 mg; Cu, 15,750 mg; Fe, 26.250 mg; I, 1.470 mg; Mn, 41.850 mg; Zn, $77.999 \mathrm{mg}$.

3 Tylan 40.

${ }^{4}$ Composição por kg de produto (Composition/kg of product): Cu, 150 mg; Zn, $100 \mathrm{mg}$.

5 Segundo (according to) Rostagno et al. (2000).
SAEG (UFV, 2000). Para os resultados das medidas ultrasônicas in vivo (espessura de toucinho, profundidade de lombo e porcentagem de carne magra), utilizaram-se como covariável os valores correspondentes à mesma variável do início do experimento. Quando houve interação significativa, procedeu-se à comparação do nível de RAC dentro de cada nível de lisina e à comparação do nível de lisina dentro de cada nível de RAC, pelo teste t, a 5\% de probabilidade.

\section{Resultados e Discussão}

Não ocorreu efeito de interação $(P>0,10)$ níveis de lisina $\times$ níveis de RAC sobre o desempenho dos animais (Tabela 2).

Observou-se efeito $(\mathrm{P}<0,06)$ da adição de RAC sobre o peso corporal de suínos em terminação aos 21 dias de experimento, ou seja, o peso corporal de suínos suplementados com RAC em relação aos não-suplementados elevou-se em aproximadamente 3,0 kg, que corresponde a um aumento de 2,5\% no peso final dos animais. Este resultado foi semelhante ao obtido por Stites et al. (1991), que, trabalhando com suínos em terminação suplementados com 5,0 ppm de RAC, observaram aumento de aproximadamente 2,0 kg sobre o peso final, em comparação àqueles que receberam a dieta não-suplementada.

Não houve efeito $(\mathrm{P}>0,10)$ dos tratamentos sobre o consumo de ração diário (CRD) e consumo de lisina diário (CLD). Resultados semelhantes foram obtidos por Yen et al. (1990). Entretanto, Watkins et al. (1990) verificaram redução no consumo de ração, quando utilizaram 20 e 30 ppm de RAC para suínos em terminação.

Constatou-se efeito $(\mathrm{P}<0,07)$ dos tratamentos sobre o ganho de peso diário (GPD), que foi maior (138 g) nos animais consumindo ração com RAC, correspondente à melhora de 9,9\% em relação aos não-suplementados. Do mesmo modo, Jones et al. (1988), Mitchell et al. (1990) e Bark et al. (1992) também observaram aumento de, aproximadamente, 10\% do GPD nos suínos em terminação que receberam ração com RAC. Por outro lado, Adeola et al. (1990), Aalhus et al. (1990) e Mitchell et al. (1991) não notaram efeito significativo da RAC sobre o GPD, o que foi atribuído aos diferentes níveis de PB e RAC contidos nas dietas.

Os tratamentos influenciaram $(\mathrm{P}<0,06)$ a $\mathrm{CA}$, que apresentou melhora de, aproximadamente, $10,61 \%$ nos animais suplementados com RAC. Estes resultados foram similares aos obtidos por Stites et al. (1991) e Xiao et al. (1999), que trabalharam, respectivamente, com a suplementação de 5,0 e 20 ppm de RAC, para suínos em terminação. Infere-se que, provavelmente, ocorreu alteração na composição do ganho dos animais, em decorrência da suplementação de RAC. 
Tabela 2 - Peso corporal e desempenho de suínos em terminação, consumindo ração com diferentes níveis de lisina digestível suplementada ou não com ractopamina, aos 21 dias de experimento

Table 2 - Body weight and performance of finishing pigs fed diets with different digestible lysine levels supplemented or not with ractopamine at 21 days of experiment

\begin{tabular}{|c|c|c|c|c|c|c|c|c|}
\hline \multirow[t]{2}{*}{ Item } & \multicolumn{2}{|c|}{$\begin{array}{l}\text { Nível de ractopamina (ppm) } \\
\text { Ractopamine level }\end{array}$} & \multirow[t]{2}{*}{ CV (\%) } & \multirow[t]{2}{*}{$\mathrm{P}$} & \multicolumn{2}{|c|}{$\begin{array}{c}\text { Nível de lisina digestível (\%) } \\
\text { Digestible lysine level }\end{array}$} & \multirow[t]{2}{*}{ CV (\%) } & \multirow[t]{2}{*}{$P$} \\
\hline & 0,0 & 5,0 & & & 0,67 & 0,87 & & \\
\hline $\begin{array}{l}\text { Peso aos } 21 \text { dias }(\mathrm{kg}) \\
\text { Weight at } 21 \text { day }\end{array}$ & $111,57 b$ & $114,44 a$ & 2,4 & $\mathrm{P}<0,06$ & 112,76 & 113,24 & 2,4 & $\mathrm{P}>0,10$ \\
\hline $\begin{array}{l}\text { Ganho de peso diário (kg) } \\
\text { Daily weight gain }\end{array}$ & $1,257 b$ & $1,395 \mathrm{a}$ & 10,1 & $\mathrm{P}<0,07$ & 1,316 & 1,337 & 10,1 & $\mathrm{P}>0,10$ \\
\hline $\begin{array}{l}\text { Conversão alimentar }(\mathrm{kg} / \mathrm{kg}) \\
\text { Feed:gain ratio }(\mathrm{kg} / \mathrm{kg})\end{array}$ & $2,669 b$ & $2,413 \mathrm{a}$ & 7,0 & $\mathrm{P}<0,06$ & 2,603 & 2,480 & 7,0 & $\mathrm{P}>0,10$ \\
\hline $\begin{array}{l}\text { Consumo de lisina digestível }(\mathrm{g} / \mathrm{d}) \\
\text { Digestible lysine intake }(\mathrm{g} / \mathrm{d})\end{array}$ & 25,8 & 25,8 & 6,0 & $\mathrm{P}>0,10$ & $22,7 b$ & $28,8 a$ & 6,0 & $\mathrm{P}<0,05$ \\
\hline
\end{tabular}

Médias seguidas de letras distintas na mesma linha diferem $(P<0,05)$ pelo teste $F$.

Means within a row with different letters differ $(P<0.05)$ by F test.

P - Probabilidade (Probability).

Os animais que consumiram dietas contendo 5,0 ppm de RAC, possivelmente, depositaram mais carne magra e menos gordura, em razão da alteração na partição dos nutrientes pela ação da RAC. Isto resultou em alteração no metabolismo de proteínas e lipídios pelo aditivo $\beta$-adrenérgico, com o aumento da taxa e eficiência de crescimento do tecido muscular, em detrimento à deposição lipídica (Watkins et al., 1990).

Não se observou efeito $(\mathrm{P}>0,10)$ dos diferentes níveis de lisina digestível (LD) sobre os parâmetros de desempenho, exceto para o CLD, que foi maior $(\mathrm{P}<0,05)$ nos animais alimentados com a ração contendo $0,87 \%$ de LD (Tabela 2). O maior nível LD na ração proporcionou aumento de 21,2\% no CLD, sem, contudo, alterar significativamente o desempenho destes animais. Uma vez que o CRD não foi influenciado $(\mathrm{P}>0,10)$ pelos níveis de $\mathrm{LD}$, o incremento no CLD ocorreu em razão do aumento do nível de lisina na dieta. Infere-se, portanto, que o nível de 0,67\% de LD foi suficiente para atender às exigências de lisina de suínos em terminação, quando a ração não foi suplementada com ractopamina.

Não ocorreu efeito de interação $(P>0,10)$ níveis de lisina $\times$ RAC (Tabela 3) sobre o peso final, ganho de peso diário, a conversão alimentar e o consumo de ração e de lisina digestível diário, em função da suplementação de RAC, aos 28 dias de experimento.

Houve efeito $(\mathrm{P}<0,05)$ da adição de RAC sobre o peso final, ou seja, os animais que receberam a ração contendo 5,0 ppm de RAC depositaram 3,42 kg a mais no peso final, representando aumento de 2,78\%. Estes resultados foram semelhantes ao observados por Crome et al. (1996).
O maior peso final pode ser explicado pelo aumento de 123 g ocorrido no GPD, correspondendo à melhora de 9,1\%, ou seja, a suplementação de RAC influenciou $(\mathrm{P}<0,08)$ o GPD. Do mesmo modo, Xiao et al. (1999), ao trabalharem com a suplementação de 20 ppm de RAC para suínos em terminação, constataram aumento de, aproximadamente, 9\% no GPD. Por outro lado, Adeola et al. (1990) e Aalhus et al. (1990) não verificaram efeitos significativos da RAC sobre esta variável.

Os animais tratados com RAC apresentaram melhora $(\mathrm{P}<0,05)$ na $\mathrm{CA}$ de $11,97 \%$, semelhante àquela verificada por Mitchell et al. (1991). Do mesmo modo, Watkins et al. (1990) e Stites et al. (1991), ao trabalharem com dieta contendo $16 \%$ de PB, suplementada com 5,0 ppm de RAC para machos castrados, verificaram que a CA reduziu em 7,84 e 13,66\%, respectivamente. Assim, pode-se deduzir que suínos alimentados com RAC podem ser mais eficientes na utilização de alimentos em comparação aos não-suplementados, em razão da melhora significativa sobre a CA. Este resultado pode ser explicado pelo direcionamento dos nutrientes à deposição de tecido muscular, uma vez que o tecido magro requer menos energia que a síntese de gordura (Zagury, 2002).

Constatou-se que a suplementação com 5,0 ppm de RAC na ração de suínos em terminação, durante 28 dias, não afetou $(\mathrm{P}>0,10)$ o CRD e CLD dos animais. Resultados semelhantes para CRD foram obtidos por Pozza et al. (2003a), utilizando fêmeas em terminação. Entretanto, Pozza et al (2003b), trabalhando com machos castrados em terminação suplementados com 5,0 ppm de RAC, verificaram redução no CDR. Segundo Schinckel et al. (2001), a suplementação de RAC em ração de suínos melhora o peso final e a 
Tabela 3 - Peso corporal e desempenho de suínos em terminação consumindo ração com diferentes níveis de lisina digestível suplementada ou não com ractopamina, aos 28 dias de experimento

Table 3 - Body weight and performance of finishing pigs fed diets with different digestible lysine levels supplemented or not with ractopamine at 28 days of experiment

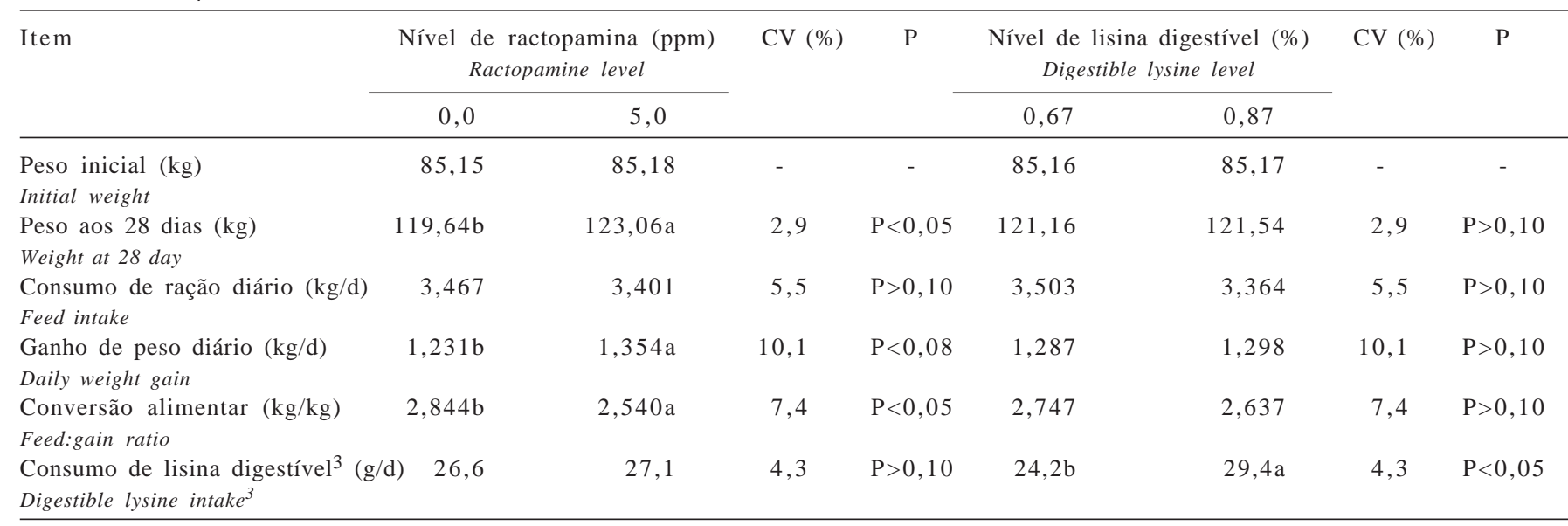

Médias seguidas de letras distintas na mesma linha diferem $(P<0,05)$ pelo teste $F$.

Means within a row with different letters differ $(P<0.05)$ by F test.

P - Probabilidade (Probability).

eficiência da carne magra, sem alterar significativamente a ingestão diária de alimentos.

Não foram verificados efeitos $(\mathrm{P}>0,10)$ dos níveis de $\mathrm{LD}(0,67$ e $0,87 \%)$ sobre o PF, CDR, GPD e CA dos animais (Tabela 3). Entretanto, o CLD aumentou em 17,69\% nos animais alimentados com dietas contendo $0,87 \%$ de LD. Uma vez que não foi observada diferença no CRD entre os tratamentos, infere-se que o incremento $(\mathrm{P}<0,05)$ no CLD ocorreu em razão do aumento do nível de lisina da dieta. Resultado semelhante foi constatado por Arouca (2003), que, ao trabalhar com níveis crescentes de lisina (0,5; 0,6; 0,7; 0,8 e 0,9\%) para suínos na fase de terminação tardia, observou efeito linear crescente sobre o consumo de lisina diário.

Como não houve efeito $(\mathrm{P}>0,10)$ dos níveis de $\mathrm{LD}$, após 28 dias de experimento, sobre o desempenho de suínos em terminação, depreende-se que o nível de $0,67 \%$ de LD foi suficiente para atender às exigências de lisina em suínos na fase de terminação.

Não ocorreu efeito da interação $(P>0,10)$ níveis de lisina $\times$ RAC sobre as características de carcaça, em função da suplementação de RAC e dos níveis de LD aos 21 dias de experimento (Tabela 4).

Não houve efeito $(\mathrm{P}>0,10)$ dos tratamentos sobre a

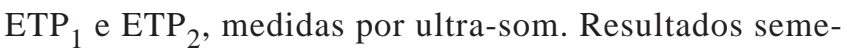
lhantes foram obtidos por Stites et al. (1991), que, ao avaliarem níveis crescentes de RAC (0, 5, 10 e 20 ppm), e Aalhus et al. (1990), utilizando 10 ppm de RAC, também não verificaram efeito significativo da RAC sobre a ETP e ETP ${ }_{2}$ de suínos em terminação. Por outro lado, Watkins et al. (1990) obtiveram redução de 5,16\% na $\mathrm{ETP}_{2}$.
A profundidade de lombo (PL) não foi influenciada $(\mathrm{P}>0,10)$ pelos tratamentos, corroborando os resultados observados por Adeola et al. (1990). Por outro lado, divergem daqueles de Stites et al. (1991), que observaram efeito linear sobre a PL, à medida que se elevou a concentração de RAC na dieta, resultando em aumento de $8,33 \%$ nos animais tratados com 5,0 ppm de RAC.

Não foram observados efeitos $(P>0,10)$ da suplementação de RAC, durante 21 dias, sobre a porcentagem de carne magra (PCM). Estes resultados foram diferentes dos encontrados por Watkins et al. (1990) e Stites et al. (1991), que observaram aumento de aproximadamente 3\% na PCM. Entretanto, os animais apresentaram incremento ( $\mathrm{P}<0,06)$ de 97 g na taxa de deposição de carne magra diária (TDCMD), correspondendo a incremento de $12,7 \%$, em razão da adição de RAC nas dietas, durante 21 dias.

Não houve efeito dos níveis de LD sobre as características de carcaça obtidas in vivo (Tabela 4), com exceção da TDCMD, que foi $7,14 \%$ maior $(\mathrm{P}<0,09)$ para os animais que receberam a dieta com $0,87 \%$ de $L D$, com ajuste para demais aminoácidos para proteína ideal. Isto pode ser explicado pelo fato de o maior nível de lisina contida na dieta proporcionar maior taxa de deposição protéica nestes animais. Além disso, o balanço ideal dos aminoácidos melhora a eficiência de utilização de energia para deposição de carne magra.

Não ocorreu interação $(\mathrm{P}>0,10)$ níveis de lisina $\times$ RAC sobre a espessura de toucinho, profundidade de lombo, porcentagem de carne magra e taxa de deposição de carne magra na carcaça, em função da suplementação 
de RAC e dos níveis de LD, aos 28 dias de experimento (Tabela 5).

Não houve efeito $(P>0,10)$ da suplementação de RAC sobre $\mathrm{ETP}_{1}$, ETP 2 , PL e PCM. Estes resultados são semelhantes aos encontrados por Adeola et al. (1990), utilizando suínos em terminação alimentados com uma dieta com 20 ppm de RAC, e Aalhus et al. (1990), suplementando 10 ppm de RAC durante 28 dias, que não observaram efeitos positivos da adição de RAC sobre estas características de carcaça.

Os animais suplementados com 5,0 ppm de RAC apresentaram TDCMD maior que os do grupo controle, de $103 \mathrm{~g} /$ dia, que corresponde a aumento de $13,75 \%$. Este resultado foi superior ao encontrado por Watkins et al. (1990), Stites et al. (1991) e Zagury (2002), que, ao trabalharem com a adição de 5,0 ppm de RAC para suínos em terminação, encontraram aumento de 2,7; 4,55 e 0,72\%, respectivamente.

A maior TDCMD observada nos animais suplementados com RAC, tanto aos 21 quanto aos 28 dias de experimento, pode ser explicada pelo maior GPD e pela melhora na CA. Assim, pode-se inferir que houve alteração na composição do ganho dos animais, em razão da suplementação de RAC, ou seja, os animais que consumiram dietas contendo $5 \mathrm{ppm}$ de RAC depositaram mais carne magra e menos gordura que o grupo controle. Isso ocorreu em razão da alteração na partição dos nutrientes pela ação da RAC, que resultou em

Tabela 4 - Características de carcaça obtidas in vivo com suínos em terminação consumindo ração com diferentes níveis de lisina digestível suplementada ou não com ractopamina, aos 21 dias de experimento

Table 4 - Carcass characteristics obtained in vivo with finishing pigs fed diets fed diets with different digestible lysine levels supplemented or not with ractopamine at 21 days of experiment

\begin{tabular}{|c|c|c|c|c|c|c|c|c|}
\hline \multirow[t]{2}{*}{ Item } & \multicolumn{2}{|c|}{$\begin{array}{l}\text { Nível de ractopamina (ppm) } \\
\text { Ractopamine level }\end{array}$} & \multirow[t]{2}{*}{ CV (\%) } & \multirow[t]{2}{*}{$\mathrm{P}$} & \multicolumn{2}{|c|}{$\begin{array}{c}\text { Nível de lisina digestível (\%) } \\
\text { Digestible lysine level }\end{array}$} & \multirow[t]{2}{*}{ CV (\%) } & \multirow[t]{2}{*}{$\mathrm{P}$} \\
\hline & 0,0 & 5,0 & & & 0,67 & 0,87 & & \\
\hline $\begin{array}{l}\text { Espessura toucinho no } \mathrm{P}_{1}(\mathrm{~mm})^{1} \\
P_{1} \text { backfat thickness }\end{array}$ & 14,5 & 14,4 & 12,4 & $\mathrm{P}>0,10$ & 15,1 & 13,8 & 12,4 & $\mathrm{P}>0,10$ \\
\hline $\begin{array}{l}\text { Espessura toucinho no } \mathrm{P}_{2}(\mathrm{~mm})^{1} \\
\mathrm{P}_{2} \text { backfat thickness }\end{array}$ & 11,3 & 11,3 & 10,9 & $\mathrm{P}>0,10$ & 11,4 & 11,2 & 10,9 & $\mathrm{P}>0,10$ \\
\hline $\begin{array}{l}\text { Profundidade de lombo (mm) }{ }^{1} \\
\text { Loin depth }\end{array}$ & 54,7 & 55,9 & 6,7 & $\mathrm{P}>0,10$ & 55,4 & 55,3 & 6,7 & $\mathrm{P}>0,10$ \\
\hline $\begin{array}{l}\text { Porcentagem de carne magra }(\%)^{1} \\
\text { Lean meat percentage }\end{array}$ & 58,7 & 58,7 & 2,4 & $\mathrm{P}>0,10$ & 58,5 & 59,0 & 2,4 & $\mathrm{P}>0,10$ \\
\hline $\begin{array}{l}\text { Taxa de deposição carne magra }(\mathrm{g} / \mathrm{d}) \\
\text { Daily lean meat deposition rate }\end{array}$ & $667 b$ & $764 a$ & 12,3 & $\mathrm{P}<0,06$ & $689 b$ & $742 \mathrm{a}$ & 12,3 & $\mathrm{P}<0,09$ \\
\hline
\end{tabular}

${ }^{1}$ Valores ajustados pelas mesmas variáveis no início do experimento (Values adjusted by the same variables in the beginning of the experiment).

Médias seguidas de letras distintas na mesma linha diferem $(P<0,05)$ pelo teste $F($ Means within a row with different letters differ $[P<0.05]$ by $F$ test).

P - Probabilidade (Probability).

Tabela 5 - Características de carcaça obtidos in vivo com suínos em terminação consumindo ração com diferentes níveis de lisina digestível suplementada ou não com ractopamina, aos 28 dias de experimento

Table 5 - Carcass characteristics obtained in vivo with finishing pigs fed diets with different digestible lysine levels supplemented or not with ractopamine at 28 days of the experiment

\begin{tabular}{|c|c|c|c|c|c|c|c|c|}
\hline \multirow[t]{2}{*}{ Item } & \multicolumn{2}{|c|}{$\begin{array}{l}\text { ível de ractopamina (ppm) } \\
\text { Ractopamine level }\end{array}$} & \multirow[t]{2}{*}{ CV (\%) } & \multirow[t]{2}{*}{$\mathrm{P}$} & \multicolumn{2}{|c|}{$\begin{array}{c}\text { Nível de lisina digestível (\%) } \\
\text { Digestible lysine level }\end{array}$} & \multirow[t]{2}{*}{ CV (\%) } & \multirow[t]{2}{*}{$\mathrm{P}$} \\
\hline & 0,0 & 5,0 & & & 0,67 & 0,87 & & \\
\hline $\begin{array}{l}\text { Espessura toucinho no } \mathrm{P}_{1}(\mathrm{~mm})^{1} \\
P_{1} \text { backfat thickness }\end{array}$ & 15,4 & 14,9 & 1,8 & $\mathrm{P}>0,10$ & $15,8 b$ & $14,4 \mathrm{a}$ & 1,8 & $\mathrm{P}<0,05$ \\
\hline $\begin{array}{l}\text { Espessura toucinho no } \mathrm{P}_{2}(\mathrm{~mm})^{1} \\
\mathrm{P}_{2} \text { backfat thickness }\end{array}$ & 12,1 & 11,7 & 9,3 & $\mathrm{P}>0,10$ & $12,3 b$ & $11,5 \mathrm{a}$ & 9,3 & $\mathrm{P}<0,06$ \\
\hline $\begin{array}{l}\text { Profundidade de lombo }(\mathrm{mm})^{1} \\
\text { Loin depth }\end{array}$ & 56,8 & 58,3 & 8,2 & $\mathrm{P}>0,10$ & 57,3 & 57,8 & 8,2 & $\mathrm{P}>0,10$ \\
\hline $\begin{array}{l}\text { Porcentagem de carne magra }(\%)^{1} \\
\text { Lean meat percentage }\end{array}$ & 58,2 & 58,6 & 2,1 & $\mathrm{P}>0,10$ & $58,0 \mathrm{~b}$ & $58,8 a$ & 2,1 & $\mathrm{P}<0,05$ \\
\hline $\begin{array}{l}\text { Taxa de deposição carne magra }(\mathrm{g} / \mathrm{d}) \\
\text { Daily lean meat deposition rate }\end{array}$ & $646 b$ & $749 a$ & 14,1 & $\mathrm{P}<0,06$ & $668 \mathrm{~b}$ & $727 a$ & 14,1 & $\mathrm{P}<0,06$ \\
\hline
\end{tabular}

${ }^{1}$ Valores ajustados pelas mesmas variáveis no início do experimento (Values adjusted by the same variables in the beginning of the experiment). Médias seguidas de letras distintas na mesma linha diferem $(P<0,05)$ pelo teste $F($ Means within a row with different letters differ $[P<0.05]$ by $F$ test).

P - Probabilidade (Probability). 
mudança no metabolismo de proteínas e lipídios do organismo animal, com aumento da taxa de deposição protéica, em detrimento à deposição lipídica.

O nível de 0,87\% de LD proporcionou, respectivamente, redução $(\mathrm{P}<0,05)$ da $\operatorname{ETP}_{1}(\mathrm{P}<0,06)$ e $\mathrm{ETP}_{2}$ de 1,4 e $0,8 \mathrm{~mm}$, respectivamente (Tabela 5). Entretanto, Oliveira et al. (2003), ao trabalharem com níveis crescentes de lisina total, não verificaram redução na espessura de toucinho em suínos machos castrados em terminação.

Não foi verificado efeito $(\mathrm{P}>0,10)$ dos níveis de $L D$ sobre a PL, entretanto, constatou-se efeito $(\mathrm{P}<0,05)$ dos tratamentos sobre a porcentagem de carne magra na carcaça, que melhorou 1,36\% em relação ao grupo contro- le, ou seja, os animais que receberam o nível mais elevado de LD foram 1,36\% mais eficientes para depositar carne magra na carcaça. Constatou-se ainda aumento de 8,12\% na TDCMD, que corresponde a $59 \mathrm{~g} / \mathrm{dia}$ nos animais recebendo o maior nível de LD.

Não ocorreu efeito da interação $(P>0,10)$ níveis de lisina $\times$ RAC sobre as características de carcaça (Tabela 6).

Não houve efeito $(\mathrm{P}>0,10)$ da suplementação da RAC sobre o rendimento de carcaça, rendimento de carré, a espessura de toucinho medida na altura da última costela, porcentagem de carne magra na carcaça e profundidade de lombo. Estes resultados foram semelhantes aos obtidos por Adeola et al. (1990) e Stites et al. (1991), que trabalharam

Tabela 6 - Características de carcaça de suínos em terminação, consumindo ração com diferentes níveis de lisina suplementada ou não com RAC

Table 6 - Carcass characteristics of finishing pigs fed diets with different digestible lysine levels supplemented or not with ractopamine

\begin{tabular}{|c|c|c|c|c|c|c|c|c|}
\hline \multirow[t]{2}{*}{ Item } & \multicolumn{2}{|c|}{$\begin{array}{l}\text { Nível de ractopamina (ppm) } \\
\text { Ractopamine level }\end{array}$} & \multirow[t]{2}{*}{ CV (\%) } & \multirow[t]{2}{*}{$\mathrm{P}$} & \multicolumn{2}{|c|}{$\begin{array}{c}\text { Nível de lisina digestível (\%) } \\
\text { Digestible lysine level }\end{array}$} & \multirow[t]{2}{*}{ CV (\%) } & \multirow[t]{2}{*}{$\mathrm{P}$} \\
\hline & 0,0 & 5,0 & & & 0,67 & 0,87 & & \\
\hline $\begin{array}{l}\text { Rendimento de carcaça (\%) } \\
\text { Carcass yield }\end{array}$ & 72,5 & 71,7 & 3,2 & $\mathrm{P}>0,10$ & 71,9 & 72,3 & 3,2 & $\mathrm{P}>0,10$ \\
\hline $\begin{array}{l}\text { Rendimento de pernil (\%) } \\
\text { Ham yield }\end{array}$ & $33,7 b$ & $34,7 a$ & 4,3 & $\mathrm{P}<0,05$ & 34,1 & 34,4 & 4,3 & $\mathrm{P}>0,10$ \\
\hline $\begin{array}{l}\text { Rendimento de carré (\%) } \\
\text { Carre yield }\end{array}$ & 12,2 & 12,3 & 7,4 & $\mathrm{P}>0,10$ & 12,1 & 12,5 & 7,4 & $\mathrm{P}>0,10$ \\
\hline $\begin{array}{l}\text { Espessura de toucinho (mm) } \\
\text { Backfat thickness }\end{array}$ & 15,0 & 14,8 & 15,6 & $\mathrm{P}>0,10$ & 15,2 & 14,7 & 15,6 & $\mathrm{P}>0,10$ \\
\hline Porcentagem de carne magra & 56,6 & 57,3 & 15,6 & $\mathrm{P}>0,10$ & 56,7 & 57,9 & 15,6 & $\mathrm{P}>0,10$ \\
\hline
\end{tabular}

na carcaça $(\%)$

Lean meat percentagein the carcass

Médias seguidas de letras distintas na mesma linha diferem $(\mathrm{P}<0,05)$ entre si pelo teste $\mathrm{F}$ (Means within a row with different letters differ [P<0.05] by $F$ test). P - Probabilidade (Probability).

com suínos suplementados com 20 e 10 ppm de RAC, respectivamente.

Por outro lado, com o uso da RAC foi verificada melhora $(\mathrm{P}<0,05)$ do rendimento de pernil de $2,88 \%$, valor inferior aos $7 \%$ encontrados por Uttaro et al. (1993).

Os níveis de LD também não influíram no rendimento de carcaça, rendimento de pernil, rendimento de carré, na espessura de toucinho medida na altura da última costela e porcentagem de carne magra na carcaça (Tabela 6).

Houve efeito da interação $(\mathrm{P}<0,06)$ níveis de $\mathrm{LD} \times \mathrm{RAC}$ para a profundidade de lombo (mm) (Tabela 7). Verificou-se que, no nível de 0,67\% de LD, não houve benefício da suplementação de RAC, enquanto no de $0,87 \%$ de LD constatou-se aumento de $6,16 \mathrm{~mm}$ na profundidade de lombo, correspondente a incremento de 8,75\%.
Tabela 7 - Profundidade de lombo $(\mathrm{mm})$ de suínos em terminação consumindo dietas com diferentes níveis de lisina digestível adicionadas ou não de ractopamina

Table 7 - Loin depth $(\mathrm{mm})$ of finishing pigs fed diets with different digestible lysine levels supplemented or not with ractopamine

\begin{tabular}{llcc}
\hline $\begin{array}{l}\text { Nível de lisina } \\
\text { digestível (\%) } \\
\text { Digestible lysine level }\end{array}$ & \multicolumn{2}{c}{$\begin{array}{c}\text { Nível de } \\
\text { ractopamina (ppm) } \\
\end{array}$} & \multicolumn{2}{c}{$\begin{array}{c}\text { Média } \\
\text { Ractopamine level }\end{array}$} & Mean \\
\cline { 2 - 3 } & \multicolumn{1}{c}{0,0} & \\
\hline 0,67 & $66,12 \mathrm{aA}$ & $65,19 \mathrm{aB}$ & \\
0,87 & $64,20 \mathrm{bA}$ & $70,36 \mathrm{aA}$ & 65,7 \\
Média (Mean) & 65,16 & 67,80 & \\
\hline
\end{tabular}

$\mathrm{CV}=6,6 \%$

Médias seguidas de letras maiúsculas distintas na mesma coluna diferem pelo teste $t(P<0,09)$.

Médias seguidas de letras minúsculas distintas na mesma linha diferem $(\mathrm{P}<0,06)$ pelo teste $\mathrm{t}$.

Means in the same row with different letters differ $(P<0.09)$ by t test

Means in the same row with different letters differ $(P<0.06)$ by t test. 


\section{Conclusões}

A suplementação de ractopamina (5 ppm) em dietas para suínos machos castrados em terminação, durante os últimos 21 ou 28 dias de vida, melhora o ganho de peso diário e a conversão alimentar e aumenta a taxa de deposição de carne magra diária. O efeito da ractopamina sobre a profundidade de lombo é maior em dietas contendo $0,87 \%$ de lisina digestível.

O nível de $0,67 \%$ de lisina digestível atende às exigências de suínos em terminação para o desempenho, porém o de $0,87 \%$ proporciona melhor qualidade de carcaça, diminuindo a espessura de toucinho e aumentando a porcentagem de carne magra, a taxa de deposição de carne magra diária e a profundidade de lombo.

\section{Literatura Citada}

AALHUS, J.L.; JONES, S.D.; SCHAEFER, S.D.M. et al. The effect of ractopamine on performance, carcass composition and meat quality of finishing pigs. Canadian Journal of Animal Science, v.70, n.5, p.943-952, 1990.

ADEOLA, O.; DARKO, E.A.; HE, P. et al. Manipulation of porcine carcass composition by ractopamine. Journal of Animal Science, v.68, n.11, p.3633-3641, 1990.

APPLE, J.K.; MAXWELL C.V.; BROWN D.C. et al. Effects of dietary lysine and energy density on perfomance and carcass characteristics of finishing pigs fed ractopamine. Journal of Animal Science, v.82, p.3277-3287, 2004.

AROUCA, C.L.C. Exigências de lisina para suínos machos castrados de dois grupos genéticos, na fase de terminação tardia. Belo Horizonte: Universidade Federal de Minas Gerais, 2003. 50p. Dissertação (Mestrado em Zootecnia) - Universidade Federal de Minas Gerais, 2003.

AROUCA, C.L.C.; FONTES, D.O.; FERREIRA, W.M. et al. Exigências de lisina, com base no conceito de proteína ideal, para suínos machos castrados de 95 a $122 \mathrm{~kg}$, selecionados para deposição de carne magra. Arquivo Brasileiro de Medicina Veterinária e Zootecnia, v.56, p.773-781, 2004.

BARK, L.J.; STAHLY, T.S.; CROMWELL, G.L. et al. Influence of genetic capacity for lean tissue growth on rate and efficiency of tissue accretion in pigs fed ractopamine. Journal of Animal Science, v.70, n.11, p.3391-3400, 1992.

CROME, P.K.; MCKEITH, F.K.; CARR, T.R. et al. Effect of ractopamine on growth performance, carcass composition, and cutting yields of pigs slaughtered at 107 and 125 kilograms. Journal of Animal Science, v.74, n.4, p.709-716, 1996.

JONES, D.J.; WAITT, W.P.; MOWREY, D.H. et al. Effect of ractopamine hydrochloride on growth performance and carcass composition of finisher pigs fed corn-soy diets with 5\% added fat. Journal of Animal Science, v.66 (Suppl. 1), p.324 (Abstract), 1988.

MITCHELL, A.D.; SOLOMON, M.B.; STEELE, N.C. Response of low and high protein select lines of pigs to the feeding of the beta-adrenergic agonist ractopamine (phenethanolamine). Journal of Animal Science, v.68, n.10, p.3226-3232, 1990.

MITCHELL, A.D.; SOLOMON, M.B.; STEELE, N.C. Influence of level of dietary protein or energy on effects of ractopamine in finishing swine. Journal of Animal Science, v.69, n.11, p.4487-4495, 1991.
OLIVEIRA, A.L.S.; DONZELE, J.L.; OLIVEIRA, R.F.M. et al. Lisina em rações para suínos machos castrados selecionados para deposição de carne magra na carcaça dos 95 aos $110 \mathrm{~kg}$. Revista Brasileira Zootecnia, v.32, n.2, p.337-343, 2003.

PIC. Grow - finish nutrition concepts: impact of nutrition on lean growth. Technical update, v.2, n.1, 18p. 1999.

POZZA, P.C.; NUNES, R.V.; SANTOS, M.S. et al. Efeito da Ractopamina sobre o desempenho e características de carcaça de suínos machos castrados na fase de terminação. In: CONGRESSO BRASILEIRO DE VETERINÁRIOS ESPECIALISTAS EM SUÍNOS, 11., 2003, Goiania. Anais... Goiânia: ABRAVES, 2003a. p.289-290.

POZZA, P.C.; SANTOS, M.S.; NUNES, R.V. et al. Avaliação da suplementação de ractopamina sobre o desempenho e características de carcaça de suínos fêmeas na fase de terminação. In: CONGRESSO BRASILEIRO DE VETERINÁRIOS ESPECIALISTAS EM SUÍNOS, 11., 2003 , Goiânia. Anais... Goiânia: ABRAVES, 2003b. p.291-292.

ROSTAGNO, H.S.; ALBINO, L.F.T.; DONZELE, J.L. et al. Composição de alimentos e exigências nutricionais de aves e suínos: tabelas brasileiras. Viçosa, MG: Universidade Federal de Viçosa, 2000. 141p.

SCHINCKEL, A.P.; LI N.; RICHERT, B.T. et al. Efeito da ractopamina sobre o crescimento, a composição de carcaça, e a qualidade dos suínos. In: CONFERÊNCIA INTERNACIONAL VIRTUAL SOBRE QUALIDADE DE CARNE SUÍNA, 2., 2001, Concórdia. Anais... Concórdia: 2001. p.324-335.

SCHINCKEL, A.P.; RICHERT, B.T.; HERR, C.T. et al. Development of a model to describe the compositional growth and ietary lysine requirements of pigs fed ractopamine. Journal of Animal Science, v.81, p.1106-1119, 2003.

STITES, C.R.; MCKEITH, F.K.; SINGH, S.D. et al. The effect of ractopamine hydrochloride on the carcass cutting yields of finishing swine. Journal of Animal Science, v.69, n.8, p.3094-3101, 1991.

UNIVERSIDADE FEDERAL DE VIÇOSA - UFV. Manual de utilização do programa - SAEG (Sistemas de Análises Estatísticas e Genéticas). (Versão 8.0). Viçosa, MG: 2000. $150 \mathrm{p}$.

UTTARO, B.E.; BALL, R.O.; DICK, P. et al. Effect of ractopamine and sex on growth, carcass characteristics, processing yield, and meat quality characteristics of crossbred swine. Journal of Animal Science, v.71, n.9, p.2439-2449, 1993.

WATKINS, L.E.; JONES, D.J.; MOWREY, D.H. et al. The effect of various levels of ractopamine hydrochloride on the performance of finishing swine. Journal of Animal Science, v.68, n.11, p.3588-3595, 1990.

XIAO, R.J.; XU, Z.R.; CHEN, H.L. Effects of ractopamine at different dietary protein levels on growth performance and carcass characteristics in finishing pigs. Animal Feed Science and Technology, v.79, n.1, p.119-127, 1999.

YEN, J.T.; MERSMANN, H.J.; HILL, D.A. et al. Effects of ractopamine on genetically obese and lean pigs. Journal of Animal Science, v.68 n.11, p.3705-3712, 1990.

ZAGURY, F.T.R. Efeito da ractopamina na ração sobre o crescimento, composição da carcaça e qualidade de carne de suínos. Belo Horizonte: Universidade Federal de Minas Gerais, 2002. 46p. Tese (Doutorado em Ciência Animal) Universidade Federal de Minas Gerais.

WILLIAMS, N.H.; CLINE, T.R.; SCHINCKEL A.P. et al. The impact of ractopamine, energy intake, and dietary fat on finisher pig growth performance and carcass merit. Journal of Animal Science, v.72, p.3152-3162, 1994. 